\title{
A review of the management of perforated duodenal ulcers at a tertiary hospital in south western Nigeria
}

\author{
*Etonyeaku AC ${ }^{1}$, Agbakwuru EA ${ }^{1}$, Akinkuolie $\mathrm{AA}^{1}$, Omotola $\mathrm{CA}^{1}$, Talabi $\mathrm{AO}^{1}$, Onyia $\mathrm{CU}^{1}$, Kolawole \\ $\mathrm{OA}^{1}$, Aladesuru $\mathrm{OA}^{1}$
}

1. Department of Surgery, Obafemi Awolowo University Teaching Hospital Complex, Ile-Ife, Nigeria. 2. Department of Surgery, Bingham University Teaching Hospital, Jos Nigeria.

\begin{abstract}
Background: Gastro-duodenal perforations are common and may complicate peptic ulcer disease. Management is often by surgical closure.

Objective: To determine the patterns of presentation and mode of management of duodenal ulcer perforations.

Methods: Retrospective review of patients with duodenal ulcer perforations seen at the Obafemi Awolowo University Teaching Hospital between June 2001 and July 2011. Patients' records were reviewed for demography, duration of disease, probable risk factors, type of surgery and complications. Data obtained was analyzed using SPSS 15.0.

Result: Forty- five patients were reviewed. There were 37 males (82.2\%). Mean age was 39.7years (range 15-78years). There were $10(22.6 \%)$ students and $8(17.8 \%)$ farmers. NSAIDs abuse (11), previous peptic ulcer disease (2), and no prior dyspeptic symptoms (20) constituted $24.4 \%, 4.4 \%$ and $44.4 \%$ respectively of cases. Seven (16\%) patients presented less than 24 hours of onset of illness. Forty one perforations (91.1\%) involved the first part of duodenum. Twenty two (49\%) patients had Graham's omental patch. We had one (2.2\%) failed repair and six (13.3\%) mortalities.

Conclusion: Late presentation of duodenal ulcer perforation is common with high mortality. Pragmatic surgical intervention with Graham's omentopexy with broad spectrum antibiotics is still commonly practiced.
\end{abstract}

Key words: Duodenal ulcers, perforations, management, Nigeria

African Health Sciences 2013; 13(4): 907 - 913 http://dx.doi.org/10.4314/ahs.v13i4.7

\section{Introduction}

Gastro-duodenal perforations are common in surgical practice and do occur as a complication of peptic ulcer disease (PUD), abuse of non-steroidal anti-inflammatory drugs (NSAIDs) and gastric cancer $^{1-6}$. Alcoholics and smokers are at higher risk ${ }^{7}$, ${ }^{8}$. Management is quite challenging as patients present late; with septicaemia, fluid and electrolyte derangements, shock and/or systemic inflammatory response syndrome.

Three decades of advances in drug treatment of peptic ulcer disease (PUD) has led to less need of elective surgery9. Emergency surgical treatment is often reserved for complications of the disease and not necessarily to cure the ulcer. These complication includes upper gastrointestinal tract

\begin{tabular}{|l|}
\hline *Corresponding author: \\
Dr. Amarachukwu C Etonyeaku \\
Department of Surgery \\
Obafemi Awolowo University \\
Ile- Ife, Osun State \\
Nigeria \\
Tel: +2348036369808 \\
Email: dretonyeaku@gmail.com \\
\hline
\end{tabular}

African Health Sciences Vol 13 Issue 4 December 2013
(GIT) bleeding; perforation of the stomach, duodenum or sites of ectopic acid production; and gastric outlet obstruction. Helicobacter pylori $(\mathrm{H}$. pylori) infection has come to play a pivotal role in the aetiopathogenesis of the disease ${ }^{10}$ and its eradication is associated with better prognosis ${ }^{11}$.

This study aimed at determining the patterns of presentation and methods of management of duodenal ulcer perforation and the outcome, at the Obafemi Awolowo Teaching Hospital Complex, south western Nigeria over, a 10year period.

\section{Methods}

The names and hospital identification numbers of all patients who had surgery for duodenal ulcer perforation between June 2001 and July 2011 were extracted from the theatre register. With this list, the case files of these patients were retrieved from the medical records department of the hospital.

The files were reviewed for patients' bio data (sex, age, occupation and tribe), history of regular use of non-steroidal anti-inflammatory medications, duration of dyspeptic symptom, 
endoscopic findings (if previously done prior to occurrence of the perforation), the symptoms each patient presented with, the interval between the time of diagnosis and time of surgery; the pre-operative medications administered to each patient prior to the surgery; the operative findings and the mode of closure of the perforation. In addition, number of days spent in the post-operative period before discharge and occurrence of any post-operative complications were also reviewed. Note is made of any re-operation. Their take-home medications, duration of their follow-up, any long term complications and post-operative endoscopic findings after discharge were also noted.

The data retrieved were entered on a spread sheet and analyzed for frequencies using the statistical packages for the social science (SPSS 15.0). Ethical clearance was obtained from the Research and Ethics Committee of the teaching hospital.

\section{Results}

A total number of 60 patients were treated within the period only 45 had complete data for the review. There were 37 males $(82.2 \%)$ and 8 females $(17.8 \%)$. Their ages ranged from 15years to 78years with a mean age of 39.7 years. Majority of the patient were in age group 21-44years (table1).

Table 1: showing age distribution of patients

\begin{tabular}{lll} 
Age group (years) & Frequency & $\begin{array}{c}\text { Percentage } \\
(\mathbf{\%})\end{array}$ \\
\hline$<20$ & 2 & 4.4 \\
$21-44$ & 25 & 55.6 \\
\hline $45-64$ & 15 & 33.3 \\
$>64$ & 3 & 6.7 \\
Total & 45 & 100.0
\end{tabular}

Students $(10,22.2 \%)$ and farmers $(8,17.8 \%)$ were more compared to other occupational groups (table 2).

Table 2: showing the occupation of patients

\begin{tabular}{lll}
$\begin{array}{ll}\text { Occupation } \\
\text { Driver }\end{array}$ & Frequency & $\begin{array}{l}\text { Percent } \\
4.4\end{array}$ \\
\hline Farmer & 8 & 17.8 \\
\hline Furniture maker & 3 & 6.7 \\
Trader & 7 & 15.6 \\
Student & 10 & 22.2 \\
Mechanic & 1 & 2.2 \\
Bricklayer & 1 & 2.2 \\
Clergy & 1 & 2.2 \\
Tailor & 5 & 11.1 \\
Teacher & 2 & 4.4 \\
Vulcanizer & 1 & 2.2 \\
Welder & 2 & 4.4 \\
Civil servant & 1 & 2.2 \\
Security man & 1 & 2.2 \\
Total & 45 & 100
\end{tabular}

The routine/regular use of NASIDs was noted in $11(24.4 \%)$ patients while $22(48.9 \%)$ did not routinely use the $\operatorname{drug}(\mathrm{s})$. There was no record on use of the drugs in $12(26.7 \%)$ of the patients. Previous history of dyspepsia and or PUD was noted in 17 (37.8\%), while $20(44.4 \%)$ never had any prior dyspepsia or PUD. There were no records as to whether or not there was prior dyspepsia in $8(17.8 \%)$ patients. For those with prior dyspepsia, the mean duration of ailment was approximately one year. Only $2(4.4 \%)$ patients in this group had endoscopic diagnosis of PUD. The duration of symptoms at presentation ranged from less than 24 hours $(15.6 \%)$ to 14 days $(2.2 \%)$. The initial pain was epigastric, umbilical, loin or lower abdomen in 31(68.9\%), 11(24.4\%), 2(4.4\%) or $1(2.2 \%)$ of the patients respectively.

Sixteen patients $(35.6 \%)$ presented in shock states with six of them having features of systemic inflammatory response syndrome. Of the latter, one was less than 45years old three were 45-64years while the remaining two were above 64years. Thirty six $(80 \%)$ patients were classified, using the American Society of Anaesthesiologist (ASA), as ASA 4E while nine $(20 \%)$ were classified as ASA 5E.

Most patients $(37,82.2 \%)$ had surgery within 24 hours of diagnosis and admission while six $(13.3 \%)$ and two $(4.4 \%)$ respectively had surgery on the second and third day post diagnosis.

Intra-operative findings included perforation in anterior aspect of first part of the duodenum in $41(91.9 \%)$ of cases; with size of the perforations ranging from $0.5 \mathrm{~cm}-2 \mathrm{~cm}$ in widest diameter. Twenty two (49\%) patients had Graham's omental patch repair, $13(29 \%)$ had simple closure with omental reinforcement while $10(22 \%)$ had just 
simple closure. One (2.2\%) patient had pyloroplasty. None of the patients had anti-ulcer surgery. Thirteen $(29 \%)$ patients had any form of medical treatment for PUD before surgery while 14(31.1\%) had the treatment after surgery. Parenteral ciprofloxacin and metronidazole were the drugs of choice in the perioperative period.

Post-operative hospital stay (table 3) ranged from 6 days to 33 days, with about 16(35.6\%) patients spending less than 10 days.
Post-operative complications (tables 4 \& 5) included: surgical site wound infection in $8(17.8 \%)$, intraabdominal abscess collection in 4(8.9\%), adult respiratory distress syndrome (ARDS) in $4(8.9 \%)$ patients; failed primary repair in a patient $(2.2 \%)$ who had simple closure of defect, and adhesive bowel obstruction in another patient $(2.2 \%)$. Six patients died (mortality rate of $13.3 \%$ ) with the mean average age of those that died at 47 years.

Figure 3: Effect of duration of perforation at presentation on duration of hospital stay

\begin{tabular}{llll}
\hline $\begin{array}{l}\text { Duration of } \\
\text { perforation (days) }\end{array}$ & \multicolumn{3}{l}{ Duration of hospital stay (days) } \\
\cline { 2 - 4 } & $1-7$ & $8-14$ & $>14$ \\
\hline$<1$ & 2 & 1 & 0 \\
1 & 2 & 6 & 1 \\
2 & 1 & 2 & 0 \\
3 & 1 & 4 & 1 \\
$>3$ & 3 & 5 & 7 \\
\hline p-value & 0.083 & &
\end{tabular}

Figure 4: Relationship between duration of perforation and post-operative complication

\begin{tabular}{|c|c|c|c|c|c|c|c|c|c|}
\hline \multirow{2}{*}{$\begin{array}{l}\text { Duration of } \\
\text { perforation } \\
\text { (days) }\end{array}$} & \multicolumn{9}{|c|}{ Complication } \\
\hline & atelectasis & Malaria & ARF & ARDS & Pn & eumonia & $\begin{array}{l}\text { Wound } \\
\text { infection }\end{array}$ & $\begin{array}{l}\text { Intra-abdominal } \\
\text { abscess }\end{array}$ & Death \\
\hline$\overline{1}$ & 0 & 0 & 0 & ( & & 1 & 1 & 2 & \\
\hline $2-3$ & 0 & 1 & 0 & 1 & & 0 & 2 & 1 & 1 \\
\hline $3-5$ & 1 & 0 & 0 & 2 & & 0 & 3 & 1 & 3 \\
\hline$>5$ & 0 & 0 & 1 & 1 & & 0 & 2 & 2 & 0 \\
\hline $\mathrm{p}$-value & 0.052 & 0.052 & & 052 & .052 & 0.052 & 0.052 & 0.052 & 0.199 \\
\hline
\end{tabular}

Figure 5: Relationship between interval before surgery and post-operative complication

\begin{tabular}{lllccc}
\hline Complication & \multicolumn{6}{c}{ Duration } & from & presentation & to surgery (days) & p-value \\
\cline { 2 - 6 } & $<\mathbf{1}$ & $\mathbf{1}$ & $\mathbf{2}$ & $\mathbf{3}$ & $\mathbf{3}$ \\
\hline Atelectasis & 0 & 1 & 0 & 0 & 0.176 \\
Malaria & 0 & 0 & 0 & 1 & 0.176 \\
Acute Renal Failure & 0 & 1 & 0 & 0 & 0,176 \\
Adult Respiratory Distress Syndrome & 0 & 1 & 2 & 1 & 0.176 \\
Pneumonia & 0 & 0 & 0 & 1 & 0.176 \\
Wound Infection & 1 & 1 & 2 & 4 & 0.176 \\
Intra-abdominal abcess & 1 & 1 & 1 & 1 & 0.353 \\
Bowel Obstruction & 0 & 0 & 1 & 0 & 0.353 \\
Re-operation & 1 & 1 & 2 & 0 & 0.065 \\
Death & 2 & 1 & 3 & 0 & 0.014 \\
\hline
\end{tabular}


Four patients were re-operated (for intra-abdominal collections and failed primary repair). Follow-up after discharge from the hospital ranged from 1 week to 2 years with an average of 24 weeks. Only 2 patients had post-operative upper G.I. endoscopy as a follow- up investigation, which was normal.

\section{Discussion}

Peptic ulcers are circumscribed loss of epithelial tissue of the gastro-intestinal tract due to corrosive effect of the gastric juice. They occur when there is a breech in the normal mucosal barrier, when excessive acid is produced, or normal gastric juice comes in contact with a mucosa not adapted to its effects. Breech in mucosa barrier may be from Helicobacter pylori (H.pylori) infection, diet (alcohol), social habits (smoking) or drugs (NSAIDs). Cigarette smoking and the indiscriminate use of ulcerogenic drugs (like non-steroidal anti-inflammatory drugs and corticosteroids) have be implicated as probable causes in as much as $75 \%$ and $30 \%$ respectively ${ }^{1}$. Additional risk factors include advanced age, male gender, alcohol abuse, and medically debilitating comorbidities $^{12,13}$.

Duodenal perforation is a common complication of PUD. This study shows a prevalence rate of about 4-5cases per year in the study period. This is similar to observation earlier in Ile- Ife ${ }^{14}$ and other centres ${ }^{15,16}$. This may be attributable to indiscriminate use of antibiotics and proton pump inhibitor (PPI) which are effective in ulcer care; and are common over the counter (OTC) drugs in our environment. There has been a steady increase in number of private health facilities, some of them offering specialist surgery and medical services. However, in general, the incidence rate of perforated duodenal ulcer appears not to have changed $^{14,17}$. It is more common in males than females ${ }^{17-19}$. In our study, it was five times more common in males than females, and this is similar to findings in previous reviews $s^{4,2}$, but at variance with findings by Watt et $\mathrm{al}^{20}$. It appears to be a disease of the young and middle especially males, as our study suggests (93.3\%). We observed that $27(60 \%)$ and $15(33.3 \%)$ were in the young and middle age groups respectively; with mean age between 39.7 years: collaborating earlier works ${ }^{14,16-19}$. However Ohene-

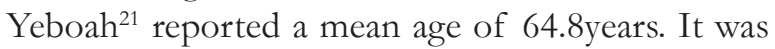
also seen in women because of increasing rate of smoking amongst them (particularly elderly women): this however is not common in our environment.
Also implicated in aetiopathogenesis is the use of NSAIDs in all the age groups $s^{1,2,20,22,23}$.

Students formed the modal occupation group; it is still not clear if the was a chance finding, or what the risk factors in them were. It may however, be attributed to use of ulcerogenic substances like xanthine and hypoxanthine present in coffee ${ }^{24}$ commonly used as stimulant for reading. This contrasts with earlier findings, in this community, of higher prevalence amongst working class individuals ${ }^{14}$. Consistent with findings elsewhere, fewer patients had dyspepsia prior to presentation compared to those who did not ${ }^{14,15,25}$. Use of ulcerogenic drugs like NSAIDS was low compared to the reports from Ghana ${ }^{2,21}$. This may be due to the younger age groups in our study: long term NSAID use is common in the elderly for care of osteoarthritis. Abdominal pain was the most common presenting complaint.

We found a sizeable proportion having centrally located pain; this may be due to gastromegaly which has been noted in patients with chronic duodenal ulcer ${ }^{26}$. Seven $(15.6 \%)$ patients presented within 24 hours from time of onset of symptom(s); this is low when compared with findings of $46.2 \%$ and $47.3 \%$ elsewhere ${ }^{2,15,19}$. Thirty seven $(82.2 \%)$ patients had surgery on or before the $24^{\text {th }}$ hour on admission which is fair compared to a study in southwest Nigeria ${ }^{14}$ but a far cry from better result by Bin-Taleeb et $\mathrm{al}^{19}$. Surgical care of PUD used to be fashionable in times past, but has been relegated to the background in the face of great success with medical therapy (mainly PPIs and $\mathrm{H}$. pylori eradication protocols). Surgery in now required for complications like perforation (closure or omental plug), gastric outlet obstruction (drainage) and massive haemorrhage (under-running of bleeder) not amenable to endoscopic intervention.

C.J. Cellan-Jones in 1929 reported 51 cases of perforated duodenal ulcer treated with a patch of omentum sutured over the perforation ${ }^{27}$. Later, in 1937, Roscoe Graham of Toronto reported 51 cases treated with omental patch closure in essentially the same fashion, though his technique was a transverse rather than a longitudinal positioning of the omental patch (by Cellan-Jones) along the long axis of the duodenal perforation, a modification thought to reduce the incidence of duodenal stenosis ${ }^{28}$. Dragstedt, in 1949, came up with the finding that vagotomy could reduce gastric acid, which paralleled a significant reduction in peptic ulcer diseases ${ }^{29}$. However the addition of a definitive acid- 
reducing procedure at same surgery with the repair of duodenal perforation seems to add to the risk for mortality and morbidity without appreciably improving the long-term outcome. ${ }^{9}$ Gupta et al identified three distinct types of perforated duodenal ulcers ${ }^{4}$. The first are small perforations that are easy to manage with low morbidity and mortality. The second are "large" perforations that are not uncommon, and which still have the best of results even with omental patch repair. The third are "giant", which exceed $3 \mathrm{~cm}$ in diameter, and are extremely uncommon. In an emergency setting, the patients are often critically ill and definitive anti- acid procedure along with closure of perforation is not advisable. Omental patch repair is simple, and still remains dependable for closure of even large perforations up to $3 \mathrm{~cm}$ in size $\mathrm{e}^{4}$. Patch closure alone is enough for duodenal perforation in light of the low recurrence rate of PUD ${ }^{16}$ especially when $\mathrm{H}$. pylori eradication is achieved. It has been noted that eradicating $\mathrm{H}$. pylori infection reduced significantly ulcer recurrence at a year later following repair of perforation ${ }^{11}$.

No record was seen of attempts at $\mathrm{H}$. pylori eradication therapy in our study. Haphazard attempts were made at eradication, though not documented as such: as antibiotics were given alongside cimetidine, ranitidine or omeprazole. By Gupta's classification our patients had either type 1 or type 2 , but none had type 3 perforation. The mortality rate of $13.3 \%$ (6/45) is higher than reported by Dakubo, Plummer, Keremu and $\mathrm{Otu}^{2,18,25,30}$ but lower than findings by Lawal and Nuhu. ${ }^{14,15}$

Five out of the six patients that died had Graham's repair; this result is poor compared to 95.8\% success rate by $\mathrm{Abid}^{31}$. These patients presented in shock states, with SIRS and preoperatively were classified as ASA 5E. These can be attributed to, amongst other probable causes ${ }^{32}$, late presentation (outside the golden 8 hours when bacteria peritonitis succeeds chemical peritonitis). Post-operative wound infection rate of $18.9 \%$ was not un-expected as the wound was classified 'dirty' ab initio. This is again was higher than what Abid et al reported ${ }^{31}$. Association between the duration of the perforation before surgery on the one hand, and period of post-operative stay on the other hand was not statistically significant $(\mathrm{P}>0.05)$ and had a weak correlation $(r=0.283)$, suggesting that length of post-operative stay for these patients was probably not dependent on the delay before surgery.
Association of duration of the perforation before surgery with post-operative complications such as wound infections was also not statistically significant $(\mathrm{P}>0.05)$ with a weak correlation $(\mathrm{r}=$ $0.217)$, suggesting that wound infection occurrence was independent of delay before surgery. However, there was a strong association between the interval from diagnosis to surgery and peri-operative death $(\mathrm{P}<0.05 ; \mathrm{r}=1.000)$ as was the findings by Barut et $\mathrm{al}^{33}$ and James Y Lau et $\mathrm{al}^{34}$. We had follow-up period ranging from 1 week to 2 years (with average of 24 weeks). This is rather short follow up period may probably be due to financial difficulty on the part of our patients to sustain regular hospital follow-up visit.

Our patients were mainly from the low socio-economic class based on their occupation. This will no doubt impacted negatively on available resources to access quality care. As noted earlier, delayed presentation, regular use of NSAIDs and other OTC drugs were common. Though the study did not seek for prevalence of H.pylori, it has been noted to be high amongst the low socio-economic group. Also the erroneous belief amongst patients that there is really no need for regular follow-up once the operative wound has healed with little or no immediate or early post-operative sequels may also account for the low follow-up period. Moreover, despite the availability of endoscopy services, patronage was low. This again could be due to financial constraint on the part of the patients, or clinicians not insisting enough, or probable poor communication between patients and their surgeons.

\section{Limitations}

This is a retrospective review and vulnerable to poor record keeping as noted in the incomplete data in $25 \%$ of the total patients managed. The rather short mean follow-up period would not allow categorical statement on outcome of care: a randomized prospective study (on-going) would address this.

\section{Conclusion}

DU perforation is predominantly a disease of middle aged men. Our patients presented late. Graham's omentopexy or simple closure with omentum reinforcement, were the common repair methods deployed. Utilization of endoscopic services was low within the study period. We recommend a prospective study, preferable a multicentre one, to ascertain the epidemiology, risk and prognostic factors of the disease. Health education 
aimed at improving health care seeking habit of the population would also be beneficial.

\section{Acknowledgement}

Professors Arigbabu AO, Akinola DO, Lawal OO, Adesunkanmi ARK and Drs. Alatise OI and Adisa $\mathrm{AO}$, whose patients' data were included in the study.

\section{References}

1. Svanes C. Trends in Perforated Peptic Ulcer: Incidence, Aetiology, Treatment and Prognosis. World J. Surg. 2000; 24: 277 - 83.

2. Dakubo JC, Naaeder SB, Clegg-Lamptey JN: Gastroduodenal pepetic ulcer perforation. East Afri Med J 2009; 86(3) 100-9.

3. Chalya et al.: Clinical profile and outcome of surgical treatment of perforated peptic ulcers in North-western Tanzania: A tertiary hospital experience. World Journal of Emergency Surgery 2011; 6:31. (10pages). Available from: http:// www.wjes.org/content/6/1/31.

4. Gupta S., Kaushik R. The Management of Large perforations of Duodenal Ulcers. BMC Surgery. (2005). 5: 15.

5. Hill AG. Management of perforated duodenal ulcer. In: Holzheimer RG, Mannick JA, editors. Surgical Treatment: Evidence-Based and Problem-Oriented. Munich: Zuckschwerdt; Available from: http:/ /www.ncbi.nlm.nih.gov/ books/NBK6926/

6. Gisbert JP, Legido J, García-Sanz I, Pajares JM. Helicobacter pylori and perforated peptic ulcer prevalence of the infection and role of nonsteroidal anti-inflammatory drugs. Dig Liver Dis. 2004; 36(2):116.

7. Rosenstock S, Jørgensen $\mathrm{T}$, Bonnevie $\mathrm{O}$, Andersen L. Risk factors for peptic ulcer disease: a population based prospective cohort study comprising 2416 Danish adults. Gut2003; 52:186-193.

8. Korman MG, Hansky J, Eaves ER, Schmidt GT. Influence of cigarette smoking on healing and relapse in duodenal ulcer disease. Gastroenterology 1983; 85: 871-4.

9. Slade Howell H. When repair is enough for perforated duodenal ulcer. www.contemporarysurgery.com. 2008; 64(11): 521 4.

10. Ng E.K., Chung S.C., Sung J.J. High Prevalence Helicobacter pylori Infection in Duodenal Perforations not caused by Non-Steroidal Anti-
Inflammatory Drugs. Br. J. Surg. 1996; 83: $1779-81$.

11. Ng EK, Lam YH, Sung JJ, Yung MY, To KF, Chan AC, Lee DW, Law BK, Lau JY, Ling TK, Lau WY, Chung SC : Eradication of Helicobacter pylori prevents recurrence of ulcer after simple closure of duodenal ulcer perforation: randomized controlled trial. Ann Surg. 2000; 231(2):153-8.

12. Morten HM, Sven A, Reimar WT, Ann MM. Preoperative Prognostic Factors For Mortality in Peptic Ulcer Perforation: A Systematic Review. Scandinavian J of Gastroenterology. 2010; 45(7-8): 785-805.

13. Werbin N., Kashtan H., Wasserman I., Wiznitzer T. Perforated Duodenal Ulcer in Elderly Patient. Can J. Surg. 1990; 33: 143 - 4.

14. Lawal OO, Fadiran OA, Oluwale SF, Campbell B. Clinical pattern of perforated prepyloric and duodenal ulcer at Ile-Ife, Nigeria. Trop Doct 1998; 28: 152-5.

15. Nuhu, A. Madziga B. Gali. Acute Perforated Duodenal Ulcer In Maiduguri. West Afr J Med. 2009; 28(6): 384-7.

16. DO Irabor: An audit of peptic ulcer surgery in Ibadan Nigeria. WAJM. 2005; 24(3); 241 245

17. Griffin G.E., Organ C.H. The Natural History of Perforated Duodenal Ulcer Treated by Suture Plication. Ann. Surg. 1976; 183(4): 382 -5 .

18. Plummer JM, McFarlane ME, Newnham. Surgical management of perforated duodenal ulcer: the changing scene. West Indian MedJ 2004; 53: 378-81

19. Bin-Taleb AK, Razzaq RA, Al-Kathiri ZO. Management of perforated peptic ulcer in patients at a teaching hospital. Saudi Med J 2008; 29: 245-50.

20. Walt R, Katschinski B, Logan R, Ashley J. Rising frequency of ulcer perforation elderly people in the United Kingdom. Lancet 1986; 3: 489.

21. Ohene-Yeboah M, Togbe B. Perforated gastric and duodenal ulcers in an urban African population. West Afr J Med 2006; 25: 205-11.

22. Wysocki A, Beben P. Incidence of Peptic Ulcer Perforations in 34-years Period. Gastroenterol. Pol. 1998; 5(2): 139 - 43.

23. Armstrong CP, Blower AL. Non-steroidal antiinflammatory drugs and life threatening complications of peptic ulceration. Gut 1987; 28: 527-32. 
24. Abu Farsakh NA. Risk factors for duodenal ulcer disease. Saudi Med J. 2002; 23(2):168-72.

25. Keremu R. T. Surgical Management of Peptic Ulcer Disease. East African Med J 2002; 79(9), 454-6

26. Reginald Miller. Gastromegaly from Chronic Duodenal Ulcer in a Child. Arch Dis Child. 1930; 5(26): 133-136.

27. Cellan - Jones C.J. A Rapid Method of Treatment in Perforated Duodenal Ulcer. British Medical Journal. 1929; 1: 1076-7.

28. Graham R.R.. The Treatment of Perforated Duodenal Ulcers. Surg. Gynaecol. Obstet. 1937; 64: $235-8$.

29. Dragstedt LR. Vagotomy for Gastroduodenal Ulcer. Ann. Surg. 1949; 122: 973 - 89.

30. Otu AA. Perforated Peptic Ulcer disease in South-Eastern Nigeria 1973-1882. Scandinavian J of Gastroenterology. 1986; 21(124): 219-222.
31. Abid KJ, Siddique T, Haider H, Ashraf M, Hanif A. Outcome of Graham's Repair in Duodenal Ulcer Perforation: An Experience of 96 Cases in West Surgical Unit of Mayo Hospital Lahore. Pakistan Journal of Medical and Health Sciences. 2010; 4(1): 75.

32. Rajesh V, Sarathchandra S, Smile SR: Risk factors predicting operative mortality in perforated peptic ulcer disease. Tropical Gastroenterol 2003; 24:148-50.

33. Barut I, Tarhan OR, Cerci C, Karaguzel N, Akdeniz Y, Bulbul N. Prognostic factors of peptic ulcer perforation. Saudi Med J 2005; 26:1255-9.

34. Lau YJ, Sung J, Hill C, Howden WC, Metz DC. Systemic Review of the Epidemiology of Complicated Peptic Ulcer Disease: Incidence, Recurrence, Risk Factors and Mortality. Digestion. 2011 Apr 14; 84 (2):102-113. 